\title{
A família e o familiar cuidador de pacientes fora de possibilidades terapêuticas: uma revisão integrativa
}

\section{The family and the family caregiver of patients beyond cure: an integrative review}

\author{
Juliana Fiorim da Encarnação ${ }^{1}$; Adriano Luiz da Costa Farinasso²
}

\section{Resumo}

O presente artigo objetiva identificar o impacto das repercussões emocionais diante da impossibilidade terapêutica, relatando os sentimentos e o processo de luto vivenciados pelo núcleo familiar, considerando as publicações latino-americanas existentes sobre o assunto. Trata-se de uma pesquisa integrativa de literatura realizada mediante a busca de artigos existentes nas bases de dados da Biblioteca Virtual em Saúde - LILACS e SciELO. Contemplaram-se artigos datados de 2003 à 2013 que abordavam as palavras-chave: família, cuidados paliativos, terminalidade e aspectos psicológicos. Foram analisadas 21 publicações existentes que demonstraram que, quando um dos indivíduos encontrara-se com uma doença fora de possibilidades terapêuticas, a necessidade de reorganização familiar fica evidente e, diante a uma enfermidade terminal, muitas vezes, um cuidador familiar se torna responsável pelo paciente, sofrendo impactos inerentes ao cuidar. Nestas condições, a família e o cuidador reagem, sofrem, enfrentam situações que afetam as suas vidas nos aspectos pessoais, emocionais, sociais e financeiros. Esses resultados enfatizam a importância da equipe de saúde voltar sua atenção aos familiares para que este período ocasione o menor número de prejuízos possíveis.

Palavras-chave: Família. Cuidados paliativos. Cuidado terminal. Estresse psicológico.

\begin{abstract}
This article aims to identify the impact of emotional repercussions related to therapeutic failure reporting the feelings experienced and the grief process experienced by family considering the Latin American publications about this theme. This is an integrative literature research performed by existing articles in the databases of the Virtual Health Library - LILACS and SciELO. The sample consisted of articles dating from 2003 to 2013 containing the keywords: family, palliative care, terminal illness and psychological aspects. The 21 articles analyzed that when one of the subjects met up with an incurable illness, the need for family reorganization is evident and to face a terminal illness a family caregiver often becomes responsible for the patient suffering impacts. Under these conditions, family and caregiver react, suffering, facing situations that affect life in personal, emotional, social and financial aspects. These results emphasize the importance of the health team turn their attention to the family in this period to give rise to the fewest possible losses.
\end{abstract}

Key words: Family. Palliative care. Terminal care. Psychological stress.

\footnotetext{
${ }^{1}$ Aluna do curso de Especialização em Saúde Mental pela Universidade Estadual de Londrina (UEL) - PR.

${ }^{2}$ Doutor em Ciências da Saúde. Professor adjunto da Universidade Estadual de Londrina - UEL.
} 


\section{Introdução}

A família caracteriza-se como primeiro núcleo de interação e socialização do indivíduo. É nela que, geralmente, constituem-se vínculos intensos que perduram durante toda a vida, tornando a enfermidade de um de seus membros um evento que produz sofrimento e alterações psicossociais em todo o núcleo. Quando a doença chega a uma fase onde não existem possibilidades terapêuticas, dúvidas e receios se instalam sobre o paciente e seus familiares (NUNES, 2010).

A possibilidade de morte nos remete a sentimentos ambíguos que são decorrentes das alterações do conceito de terminalidade. Esta etapa da vida que, a princípio, era vivenciada como natural e decorrente da condição humana, atualmente é evitada a todo custo (SILVA; ISSI; MOTTA, 2011). A sociedade tem encontrado diferentes recursos de enfrentamento diante da finitude e esta forma de olhar tem se alterado com o passar dos anos. Morrer passou a não ser mais algo inerente e sim um acontecimento extremamente traumático não apenas para o próprio paciente como também para o núcleo familiar e, portanto, grandes são as tentativas de impedi-la (MENOSSI; ZORZO; LIMA, 2012).

$\mathrm{Na}$ contramão desta tentativa de cura a todo custo, os cuidados paliativos surgem com a intenção de oferecer dignidade e humanidade no tratamento ao enfermo que se encontra em fase final ou terminal da doença. Inocenti et al. (2009), acrescenta que a abordagem paliativa apresenta maior enfoque à família, apoiando-a e dando suporte neste momento que se caracteriza como de intenso sofrimento para todo o núcleo. Esta etapa da doença e terminalidade causa extrema angústia aos familiares já que estes são depositários de grande responsabilidade sendo que, neste momento, cabe a eles decidirem o rumo do tratamento (FONSECA; REBELO, 2011).

O modo de enfrentamento dos familiares, diante à perspectiva de morte do paciente é moldado pelo sistema de crenças da família que, por sua vez, seria formatado pelas experiências de perda e luto até então vivenciados. Perez, Silva e Couto (2009) afirmam que os familiares enfrentam etapas semelhantes às atravessadas pelo paciente durante todo o percurso: diagnóstico, tratamento e cura ou morte. Entre as etapas principais encontram-se a depressão e a negação. Quando da descoberta de uma doença terminal, a família, vista como um sistema organizado, adoece conjuntamente com o enfermo geralmente se culpando pelo acontecido. Ocorre uma desorganização do núcleo familiar que provoca, além das fases descritas acima, diferentes maneiras de enfrentamento: tranquilidade, esperança, medo, insegurança, confusão, apatia, desespero, desestruturação, superproteção e inclusive, o luto antecipatório (SCHMIDT; GABARRA; GONÇALVES, 2011).

A necessidade de presença e apoio familiar são decorrentes da angústia de separação. A ameaça de separação com as figuras parentais provoca, futuramente, ansiedades que estimulam o paciente ao impulso primitivo de apegar-se a familiares. Nesta perspectiva, a família diante de situações de doença e morte enfrenta um rearranjo, sendo que, através desta reorganização irá construir uma nova identidade na tentativa de manter-se em equilíbrio ou homeostase (SCHMIDT; GABARRA; GONÇALVES, 2011). Sendo assim, o processo de luto familiar exige manutenções deste sistema através de reorganizações imediatas e, também, a longo prazo (SOUZA; GOMES, 2012). Os familiares precisam estar bem informados sobre a doença e seu prognóstico recebendo orientações específicas e apoio, pois tais medidas realizadas pela equipe ajudam os familiares diminuindo a ansiedade e criando atmosfera de confiança e segurança.

A família deve receber assistência durante todo o período de acompanhamento do paciente, incluindo a morte e o processo de luto. Olhar para os familiares do paciente em situação terminal deve ser considerado também como forma de humanizar o tratamento, pois através do suporte à saúde mental do núcleo, garante-se a qualidade de vida de seus membros (SALES; D’ARTIBALE, 2011). 
Nesta iminência de terminalidade da vida, a saúde mental dos indivíduos envolvidos pode ser fortemente atingida. Frente a este momento de crise, qual o impacto para os familiares diante do paciente sem possibilidades terapêuticas? Através da sistematização das publicações existentes sobre o tema, o presente artigo objetiva identificar o impacto das repercussões emocionais diante da impossibilidade terapêutica relatando os sentimentos vivenciados bem como, descrevendo o processo de luto experimentado pelo núcleo familiar.

\section{Metodologia}

Este estudo empregou a revisão integrativa da literatura - método que permite a síntese de estudos relacionados ao tema a fim de obter entendimento aprofundado a respeito deste, contribuindo assim, para futuras discussões e reflexões (MENDES; SILVEIRA; GALVÃO, 2008). O presente estudo foi realizado utilizando-se artigos publicados em bases de dados científicos eletrônicos que abordavam as experiências familiares diante à doença, à terminalidade e aos cuidados paliativos.

Foram analisados artigos publicados nos idiomas português e espanhol, sendo desconsiderados os datados anteriormente ao ano de 2003. A revisão foi realizada no mês de junho de 2013 através da Biblioteca Virtual de Saúde que comporta as bases de dados LILACS (Literatura Latino Americana e do Caribe de Informações em Ciências da Saúde) e SciELO (Scientific Electronic Library Online) utilizando as seguintes palavras-chave: família, cuidados paliativos, terminalidade e aspectos psicológicos, desta maneira, foram encontrados 303 artigos relacionados ao tema proposto. Do total de artigos encontrados, 84 foram selecionados pelo título, posteriormente, 21 foram escolhidos através do conteúdo dos resumos, bem como pela sua disponibilidade integral, gratuita e online a fim de serem analisados e sintetizados de forma reflexiva.
Objetivou-se sintetizar junto às 21 publicações encontradas aspectos relacionados às vivências e dificuldades familiares bem como os sentimentos experimentados durante o processo de doença, morte e morrer. Priorizou-se, ainda, verificar as situações vividas no cotidiano do cuidar e, também, os problemas enfrentados por este cuidador diante às circunstâncias presenciadas no processo de terminalidade.

\section{Resultados e Discussão}

Por meio da análise dos 21 artigos verificou-se que todos os estudos foram selecionados pela base de dados LILACS (Literatura Latino Americana e do Caribe de Informações em Ciências da Saúde), entretanto $03(14,29 \%)$ também puderam ser encontrados através do SciELO (Scientific Electronic Library Online). Destes estudos, 16 (76,19\%) eram pesquisas qualitativas já, dois (9,52\%) apresentaram-se como pesquisas quantitativas/ qualitativas e 03 (14,29\%) caracterizaram-se como revisões de bibliografia. Dos artigos encontrados, 19 (90,48\%) estavam escritos em língua portuguesa enquanto que dois $(9,52 \%)$ encontravam-se em idioma espanhol.

Cabe ressaltar que cinco $(23,81 \%)$ referiramse apenas aos familiares em geral, nove $(42,86 \%)$ apenas aos familiares cuidadores e sete $(33,33 \%)$ integraram a família e o familiar cuidador em seus resultados. Destes artigos, dez (47,62\%) associaram os cuidados paliativos ao tema família.

Observou-se ser mais comum nestes estudos, pacientes terminais adultos, tendo sido encontrado apenas três $(14,29 \%)$ textos relacionados à criança, um $(4,76 \%)$ relacionado a adolescentes e quatro $(19,05 \%)$ referentes ao paciente idoso.

Dentre os artigos analisados apenas três (14,29\%) foram escritos pela área de psicologia, 12 (57,14\%) pela área da enfermagem e, seis $(28,57 \%)$ escrito por outras categoriais profissionais (terapeutas ocupacionais, médicos e assistentes sociais). A 
partir deste dado, observa-se uma predominância dos estudos realizados pela enfermagem. Tal constatação pode ser decorrente do fato desta categoria estar mais próxima do cuidado com o paciente, observando sempre a importância do papel do familiar nesta etapa.

Os dados obtidos nesta revisão possibilitaram a visualização das diferentes percepções dos familiares diante do adoecimento e morte de um de seus membros bem como, as observações do familiar cuidador frente às necessidades e expectativas de tratamento e cura do paciente fora de possibilidades terapêuticas. Desta pesquisa surgiram três categorias de análise a saber: morte e cuidados paliativos; a família; o familiar cuidador.

\section{Morte e cuidados paliativos}

Ao longo dos anos o processo de morrer passou por diversas conotações. Em linhas gerais, a morte passou de um evento natural da vida humana para uma situação evitada a todo custo. Tal percepção teve grande embasamento nos novos modelos médicos onde, curar é o preceito básico (SILVA; ISSI; MOTTA, 2011). Observamos que a terminalidade da vida produz nos indivíduos que encontram-se diante a pessoa em processo terminal sentimentos de indiferença, culpa, tristeza, impotência e medo de evidenciar os próprios sentimentos.

A terminalidade da vida é considerada como inimiga, no entanto é a única certeza que possuímos. A possibilidade de morte produz desconforto, sensação de abandono e aniquilamento e, ao vivenciar o processo de morte do outro lembramonos da nossa própria finitude algo que, na maioria das vezes não nos agrada, nos enche de angústia. Portanto, a doença traz à tona a mortalidade humana que tentamos, sem sucesso, mascarar. "A situação da doença, em um primeiro momento, rompe as atividades cotidianas e, ao mesmo tempo, abre a possibilidade para olhar a si mesmo e para a morte que se faz mais presente" (MENOSSI; ZORZO; LIMA, 2012, P. 3).
Muito se tem feito para curar doenças que estão em fase avançada e, nesta tentativa de prolongamento da vida, profissionais e familiares se esquecem de proporcionar dignidade ao paciente. $\mathrm{Na}$ descoberta de uma doença é preciso avaliar se o tratamento empreendido realmente proporcionará ao doente alguma melhora em seu quadro clínico ou se o paciente encontra-se fora de possibilidade terapêutica - no qual não é possível a reversão do quadro clínico. Atualmente, incluem-se nas doenças fora de possibilidades terapêuticas: câncer, AIDS, demências, doenças neurológicas progressivas, insuficiência cardíaca congestiva, doença pulmonar obstrutiva crônica, insuficiência renal, sequelas neurológicas e outras situações incuráveis e em progressão (SEKI; GALHEIGO, 2010). Em crianças, a atenção é voltada para "doenças limitantes da vida". Importante salientar que, dentre as doenças consideradas, o câncer é a que possui maior representação social. Esta terminologia 'câncer' reúne um conjunto de mais de 200 doenças distintas de múltipla causalidade e diferentes formas de tratamento e prognóstico (SCHMIDT; GABARRA; GONÇALVES, 2011; CAPELLO; VELOSA; GUIMARÃES, 2012). Contudo, este diagnóstico surge permeado pela certeza de morte devido às crenças sociais.

Em decorrência da necessidade de um olhar humanizado ao paciente surge o movimento dos cuidados paliativos que visam "o estabelecimento do cuidado que não acelere a chegada da morte, nem a prolongue com meios desproporcionais" (INOCENTI; RODRIGUES; MIASSO, 2009). Esta abordagem busca proporcionar alívio dos sintomas a fim de que o paciente tenha qualidade de vida durante os dias que lhe restarem, contudo, não se propondo a curar a enfermidade. A opção pelos cuidados paliativos deve ser estudada caso a caso. Os cuidados paliativos podem ser definidos ainda como medida terapêutica, sem intenção curativa que visa diminuir as repercussões negativas da doença tanto em ambiente hospitalar quanto domiciliar. Silva et al. (2011), apontam que, 
uma vez constatada a impossibilidade de cura, a abordagem paliativa deve ser considerada com o intuito de que o paciente seja atendido em todas as suas necessidades - físicas, emocionais, sociais e espirituais. Seki e Galheigo (2010) ressaltam a importância de respeitar a visão do paciente e de seus familiares que estas são pautadas na cultura, na espiritualidade, nos costumes, nos valores e credos de cada indivíduo diante da morte.

No que se refere aos familiares e cuidadores, os cuidados paliativos ofertam apoio diante às dificuldades e suporte para que os mesmos possam elaborar o luto diante à perda de um ente querido. O paliativismo tem, ainda, por objetivo humanizar o cuidado e, através de uma assistência multiprofissional auxiliará familiares a resolver e elaborar as situações pendentes para que, na ocorrência da morte do paciente cada familiar possa retomar sua vida com o menor prejuízo possível.

\section{A família}

O núcleo familiar constitui-se como a primeira unidade de interação de cada indivíduo, através dele nos socializamos, aprendemos a conviver em grupo. A família possui um conjunto de valores e crenças que norteiam a vida de cada um de seus membros. "A família é uma unidade formada por seres humanos que se percebem através de laços afetivos, de interesse ou de consanguinidade dentro de um processo histórico de vida, mesmo quando essas pessoas não compartilham um mesmo ambiente" (NUNES, 2010). Importante salientar que, nesta revisão, tratamos como família não apenas parentes consanguíneos mas, sim, todos os indivíduos que fazem parte do círculo afetivo do paciente.

A descoberta de uma doença no seio familiar abala a todos os membros, contudo cada indivíduo é afetado de forma singular. As relações familiares - algumas bastante próximas, outras estremecidas interferem diretamente e diferentemente na comoção de cada familiar. Independente da qualidade destas relações é o núcleo familiar que acompanha o processo de doença e terminalidade deste indivíduo. Assim, a presença de uma morbidade estende-se a toda estrutura familiar impondo ao núcleo uma necessidade de reorganização emocional alterando, inclusive, as relações interpessoais presentes no contexto - deve-se levar em consideração que, em situações com proximidade da morte podem surgir dificuldades não solucionadas durante a vida (SCHMIDT; GABARRA; GONÇALVES, 2011).

Existe ainda, muitas vezes, a necessidade de rearranjo em situações práticas como, por exemplo, modificação na situação econômica e na dinâmica familiar. A família diante à situação de doença e morte, perde a homeostase (FONSCECA; REBELO, 2011). "O processo de adoecer não é apenas um acontecimento individual (...) gera desequilíbrios que vão além do aspecto corporal do doente, exigindo reorganização em diferentes dimensões da vida da família" (SOUZA; GOMES, 2012, p. 150).

No que tange às experiências emocionais vivenciadas pela família, observa-se que esta apresenta medo e angústia diante à doença e à possibilidade de morte. Perez, Silva e Couto (2009) sinalizam que os familiares vivenciam as mesmas etapas que o paciente - negação, raiva, barganha, depressão e aceitação estabelecidas por Kübler-Ross. Rezende et al. (2005) apontam para a inter-relação do sofrimento psíquico familiar com o sofrimento do doente, como uma relação direta, na qual a família e o paciente influenciamse diretamente. Entre as reações mais comuns apresentadas pode-se destacar a negação. Seki e Galheigo (2010) destacam que diante a uma doença considerada grave a família pode reagir física, emocional ou socialmente apresentando prejuízos em todas as áreas. As autoras detectam ainda a presença de sentimentos de culpa diante à doença e impotência frente ao prognóstico. Como os indivíduos, a família é um núcleo biopsicossocial e, em decorrência disto, precisa ser amparada em todos os seus aspectos. 
Os familiares possuem necessidades específicas devido às frequências elevadas de estresse, distúrbios de humor e ansiedade. Nunes e Rodrigues (2012) relatam a existência de sentimentos ambíguos por parte da família, pois, estes sabem da gravidade e da remota possiblidade de cura, entretanto, nutrem a expectativa de permanência da vida. Souza e Gomes (2012) diferenciam os sentimentos vivenciados durante o processo de enfrentamento da doença. Os autores observam que na descoberta da enfermidade a família precisa apoiar o doente e, simultaneamente, aceitar a presença de uma doença terminal. Na fase inicial de tratamento choque, desespero, angústia e revolta são responsáveis pela reviravolta na situação familiar. No decorrer do tratamento há a tentativa familiar de 'normalidade' diante às situações cotidianas.

Quando a terminalidade ameaça os sentimentos enfrentados são de perda e pena e, nesta fase, pontuam-se ainda sentimentos de raiva e ódio bem como, depressão e negação. Não são raras as vezes em que familiares, pacientes e médicos estabelecem a conspiração do silêncio onde ambos evitam falar sobre a doença e a possibilidade de morte. Notase, então, a necessidade de manter a família ciente sobre a evolução da doença através de informações claras como forma de apoio (SOARES, 2007).

Em 33,33\% dos estudos observou-se que as percepções familiares são calcadas no imaginário, nas crenças que são mantidas pela sociedade. Tais crenças, na maioria das vezes, dificultam o processo de aceitação da doença principalmente naquilo que se refere ao temor diante à terminalidade da vida. Cabe ressaltar que a vivência do luto ocorre antes mesmo do óbito, este é o luto antecipatório. Durante o processo de doença a família inicia um processo de despedida do ente querido e daquilo que este significa na composição familiar. Aos poucos o núcleo se reorganiza prática e emocionalmente de forma que, quando do falecimento deste familiar a dor e o sofrimento sejam amenizados (SCHMIDT; GABARRA; GONÇALVES, 2011; SALES; D'ARTIBALE, 2011). A este respeito pouco pode- se constatar, pois a vivencia do luto antecipatório foi abordada apenas em dois dos artigos analisados $(9,52 \%)$.

Os familiares precisam conservar as funções familiares e sociais, dentro do possível, mantendo a identidade familiar reconhecendo vagarosamente a futura estrutura do núcleo, sem o paciente. As demandas apresentadas pelos familiares são diferentes dependendo da forma de atenção dispensada a eles. $\mathrm{O}$ familiar com paciente hospitalizado sente-se mais seguro por ter alguém exercendo os cuidados, entretanto, manifesta dúvidas quanto ao prognóstico da doença. Observase indispensável identificar as demandas individuais e coletivas a fim de proporcionar suporte necessário (NUNES; RODRIGUES, 2012). Soares (2007) acrescenta que no ambiente de UTI os familiares apresentam demandas específicas como: estar próximo ao paciente; sentir-se útil; estar informado a respeito do quadro clínico e das medidas que estão sendo tomadas; estar seguro pela decisão de limitação do tratamento curativo; ser confortado podendo expressar seus sentimentos e angústias encontrando um significado para a morte. O período de internação produz maiores inseguranças e incertezas nos familiares, principalmente em decorrência da representação social de morte em que estes enquadram o ambiente hospitalar. Os familiares necessitam, inclusive, de atendimento após o óbito do paciente, pois, os sintomas de estresse, ansiedade e depressão podem perdurar por algum tempo.

Têm-se como cultura popular que, quanto mais elevada a faixa etária do paciente maior facilidade se dará a aceitação da morte, contudo, a forma como luto atingirá os familiares não depende apenas deste critério mas, também, do papel que este paciente desempenhava no núcleo familiar. Na ocorrência do falecimento do paciente a família passa por intenso sofrimento e dor. Estes sentimentos, por mais difíceis de serem superados, são importantíssimos para a aceitação da morte. "Quando a morte tornase algo concreto, a família se sente desorientada, 
sendo envolvida por sentimentos de angústia e dor" (SALES; D’ARTIBALE, 2011,p. 670). Sendo assim, cerca de $61,90 \%$ dos artigos analisados se referem a importância da atenção da equipe multidisciplinar dada ao familiar neste momento de luto, oferecendo suporte na dor e auxilio em situações práticas. Para facilitar a aceitação da morte é fundamental que a pensemos como um processo e não como um fim.

Observou-se ainda a importância da religiosidade, tanto para o cuidador como para toda a família. Através da crença em algo superior se tornam mais fortes suportando com os problemas decorrentes da doença e da morte do enfermo. A religiosidade aparece na grande maioria dos artigos estudados $(42,86 \%)$ como forma de enfrentamento, alivio do sofrimento e conforto (SCHMIDT; GABARRA; GONÇALVES, 2011). Familiares que não se apegaram a uma religião tiveram maiores dificuldades na aceitação da morte. A espiritualidade surge como um ponto de apoio para esta situação considerada limite.

Constata-se que, a família deve ser considerada como uma unidade de saúde para seus membros, pois, ela é fonte de cuidados, favorecidos devido à proximidade e convivência, 52,38\% dos artigos estudados corroboram com esta percepção. "Em caso de enfermidades graves, a família age, reage e interage internamente e com o contexto social em que vive para ajudar e apoiar o membro doente" (SILVA; ACKER, 2007, p.2).

\section{O familiar cuidador}

Segundo Sales e D’Artibale (2011) "compreender o cuidar enquanto oportunidade de aprendizado a partir da troca, da sensibilidade e da intenção consciente em estar junto ao outro". O ato de cuidar de um familiar muitas vezes é idealizado pela tentativa de dar apoio e aumentar a qualidade de vida deste paciente. Tal vontade leva o familiar a desempenhar novos papéis, nunca antes realizados e, para os quais, não possui qualificações.

“Cada pessoa tem sua percepção própria da enfermidade, suas expectativas e limitações (...), questões culturais e pressupostos. Em busca de manter equilíbrio familiar, tentam adaptar-se às situações que se apresentam em cuidar deste familiar adoecido" (NUNES, 2010).

Assim como o restante da família o cuidador e o paciente estão inter-relacionados em seus sintomas psíquicos. Deste modo, visualiza-se que estes cuidadores possuem fundamental importância em todos os aspectos do enfermo, inclusive nas decisões tomadas nesta etapa da vida, pois serão eles que estarão presentes durante toda a jornada do paciente.

Inúmeros motivos levam uma pessoa a assumir o cuidado de um familiar, em resumo, a decisão se baseia nos preceitos e crenças, ou seja, particularidades subjetivas que podem ser resultadas do sentimento de obrigação, de retribuição, de ordem financeira ou afetiva. Silva e Acker (2007) pontuam a existência de três motivações para a escolha do cuidador: motivação pessoal; decisão conjunta entre os familiares e; falta de opção. Fratezi e Gutierrez (2011), por sua vez, detectam os seguintes fatores preponderantes para esta decisão: gênero, idade, grau de parentesco, local de residência, situação financeira, tempo, afetividade e personalidade.

Quando a decisão é pautada pela relação afetiva com o enfermo estes sentimentos se transformam em gestos de respeito e solidariedade, amenizando o sofrimento de ambos. Porém, a decisão de cuidar pode também estar relacionada a outros fatores como: o familiar que possui maior tempo disponível ou condição financeira estável - deste modo, o familiar nem sempre se reconhece como cuidador.

Independentemente da forma como o cuidador foi escolhido é importante observar as características de personalidade de cada um deles. Estudos demonstram que, uma atitude positiva diante da vida proporcionara um cuidado positivo, com ônus menor ao cuidador, contudo, o contrário também é verdadeiro. A qualidade de vida do cuidador dependerá muito da motivação para o cuidado, pois quando o cuidar não é apenas obrigação 
pode produzir bem-estar e tranquilidade, trazendo satisfação a este familiar com a certeza de fazer o bem ao ente querido.

O cuidador disponibiliza no cuidar apenas aquilo que é capaz emocionalmente. Os recursos psíquicos pessoais e sociais influenciam diretamente na forma do cuidado. Vale ressaltar que, nem sempre a família fica satisfeita com o cuidado exercido podendo gerar então conflitos intrafamiliares importantes que, se não resolvidos, podem abalar a estrutura familiar que no momento já está caótica.

Destaca-se que, dos sentimentos positivos evidenciados pelos cuidadores, surgem sentimentos como zelo, carinho e gratificação mesmo que o trabalho seja dispendioso em vários níveis emocional, físico e financeiro. No entanto, quando os sentimentos são negativos, os cuidadores vivenciam sentimentos de tristeza, incômodo e, principalmente impotência. Para um efetivo cuidado, o familiar cuidador deve encontrar um sentido para efetuálo, atribuindo significado para este sofrimento (FRATEZI; GUTIERREZ, 2011).

Frente aos artigos encontrados, observou-se que, na maioria das vezes, o familiar cuidador é do sexo feminino - geralmente filhas e mães - "resultado da construção histórica, cultural, social e de gênero, relativa à figura feminina, interpretada como precursora do cuidado" (SILVA; ACKER, 2007). Cabe ressaltar que o estudo realizado por Rezende et al. (2010) demonstra que as mulheres apresentam maior suscetibilidade ao adoecimento e depressão causados pelo estresse ao cuidar de um familiar. Segundo o autor a ocorrência do adoecimento surge principalmente pelo excesso de trabalho, pela mudança na rotina bem como pela ausência de zelo do cuidador para consigo. Entre as vivências relacionadas ao cuidar estão: aprendizado sobre o cuidado; sofrimento físico e psíquico; dentre outros. Em decorrência destas vivências surgem as dificuldades que, através dos artigos analisados, decorrem principalmente da falta de informação e apoio externo. Aprender a ser um cuidador é um processo lento, aperfeiçoado diante à segurança que a família adquire em seu decorrer.

Entre os sentimentos experimentados pelos cuidadores diante do processo de doença e morte estão: ansiedade, depressão, culpa, solidão, dentre outros. Estes sentimentos unidos geram a sensação de impotência que, por sua vez, é comumente enfrentada através da negação - que é a busca temporária de respostas inversas à realidade.

Em linhas gerais, cuidar traz consequências na vida pessoal, social e emocional do cuidador, uma vez que "a sobrecarga do cuidado restringe atividades, traz preocupações, insegurança e isolamento e coloca o cuidador diante da morte e da falta de apoio emocional e prático" (INOCENTI ET; RODRIGUES; MIASSO, 2009). Encontram-se ainda, sentimentos ambivalentes como amor e ódio pelo doente bem como pelos cuidados necessitados. A sobrecarga financeira é um aspecto encontrado em $28,57 \%$ dos artigos sendo considerados de extrema relevância, pois o cuidador abdica de sua própria vida dedicando-se exclusivamente aos cuidados com o enfermo. Atrelado a estas consequências é importante salientar que o cuidador se torna mais suscetível a doenças físicas. Decorrente do estresse gerado durante o exercício de cuidar o familiar pode se tornar tão doente, psiquicamente falando, quanto o paciente, pois “cuidar de um adulto dependente é desgastante e implica em riscos de tornar doente e igualmente dependente o cuidador" (PEREZ et al, 2009). O cuidador ainda pode vivenciar prejuízos em sua vida social como diminuição nas relações e isolamento. Muitos cuidadores não se desapegam da vida antiga que levavam e, ao mesmo tempo, não conseguem dar conta da vida atual não se dedicando assim às necessidades presentes. Entretanto, observa-se uma anulação das vontades pessoais do cuidador, este passa a viver exclusivamente os desejos do enfermo. Perez et al (2009) corrobora afirmando que "a linha tênue de divisão entre a vida do paciente e a do cuidador desaparece, pois o cuidador passa a experimentar a vida de seu familiar doente intensamente a fim de que nada lhe falte". 
Faz-se necessário ressaltar a alternância de papéis sociais encontrados na vivência do cuidar. Estudos demonstram que muitas vezes o paciente torna-se uma pessoa infantilizada e, além desta questão emocional, o cuidador passa a realizar tarefas como se fosse a figura materna - dar comida, dar banho, alimentá-lo.

Aliado a todos estes sentimentos cuidar proporciona, ao mesmo tempo, dificuldades e bemestar. As dificuldades são decorrentes do estresse que esta atividade gera já, o bem-estar, é decorrente da sensação de missão cumprida, de ter proporcionado ao paciente conforto no final de sua vida. Sales e D’Artibale (2011) acrescentam que a sensação de bem-estar surge, geralmente, após o falecimento do doente.

Floriani e Schramm (2006) relatam que, geralmente, os cuidadores sentem-se adaptados às suas funções, mas ainda assim, evidenciam sentimentos de sobrecarga em todos os aspectos da vida o que, consequentemente, pode gerar piora no estado de saúde do cuidador (ANDRADE et al, 2012). Deste modo, o bem-estar do cuidador está diretamente ligado à sua saúde mental e esta, por sua vez, pode se encontrar seriamente abalada diante às situações de ansiedade e depressão. A qualidade de vida deste familiar que presta os cuidados deve ser constantemente verificada isto porque, no decorrer da evolução da doença os familiares sofrem transformações como um processo de adaptação. Evidenciou-se que o cuidar gera mais trabalho e responsabilidade aliado a uma maior sobrecarga emocional e um menor tempo para si, resultando em uma saúde mental afetada principalmente devido ao desgaste e estresse tornando todo o núcleo familiar doente.

Dentre os artigos analisados, destaca-se o estudo de Floriani e Schramm (2006) que se diferencia dos demais, tratando o cuidar como um exercício primordialmente negativo a este familiar. Segundo os autores, exercer o cuidado promove comprometimentos psicossociais e físicos tornando o cuidador extremamente vulnerável a doenças cardíacas dentre outros sintomas físicos. Acrescentam também a possibilidade da existência da Síndrome de Burnout caracterizada como uma reação ao estresse que provoca irritabilidade, fadiga, distúrbios no sono, depressão, entre outros.

A análise destes artigos fortalece a ideia de que os cuidadores devem ser incluídos, de fato, na equipe de cuidados para que recebam ajuda e auxílio em todas as esferas do cuidar e, principalmente, naquilo que tange aos sentimentos vivenciados e ao estresse evocado enfim, um tratamento holístico (ARRIAZA; CANCINO; SANHUEZA, 2009).

Quanto mais próximo da morte, maior é a complexidade, gerando inseguranças e um aumento dos agentes estressores, "a aproximação da morte do ente querido desperta na família e, em especial no cuidador, desgaste físico, financeiro e emocional" (FRATEZI; GUTIERREZ, 2011). Observa-se este período de cuidar como catalisador de intenso conhecimento e crescimento pessoal. O cuidador que vivencia a morte de seu familiar possivelmente irá valorizar a vida e as oportunidades, tendo maior consciência da possibilidade de finitude da mesma.

É fato que o cuidador, independentemente de sua motivação para o cuidar, sofre prejuízos em sua vida - nos aspectos físicos, psíquicos e sociais (DURÓN; MARTINEZ-JUÁREZ, 2009). Assim, torna-se de extrema importância o olhar para este familiar cuidador que apresenta grande vulnerabilidade, pois a qualidade de vida deste indivíduo precisa estar em destaque na assistência paliativa e, só assim, o cuidado com dignidade e humanidade será exercido realmente tanto em hospitais quanto no atendimento domiciliar.

\section{Conclusão}

Este estudo, através de uma revisão dos artigos publicados nos últimos dez anos, possibilitou a visualização das situações experimentadas pelos familiares diante ao processo terminal de um ente 
querido. Permitiu também, conhecer os sentimentos e dificuldades vivenciadas pelo familiar cuidador frente às necessidades especificas que este cuidar proporciona. Através dos artigos selecionados e analisados observa-se que, quando da presença de uma doença que encontra-se em fase terminal o paciente e sua família enfrentam diferentes sentimentos e desafios. Este processo terminal produz angústias e incertezas diante à possibilidade de morte desestruturando todo o núcleo familiar. As reações emocionais à doença são semelhantes entre família, cuidador e paciente e estas, se não atendidas podem dificultar ainda mais este processo. Cabe, então, à equipe de cuidados se ater não apenas centrada no paciente, mas também em sua família tratando-a como uma unidade de cuidados as quis poderão, se apoiadas, suportar o doente auxiliando em seus cuidados.

O cuidador precisa de uma atenção específica, pois vive uma situação extremamente estressante bem como um momento de aniquilamento da própria vida em prol de uma melhor atenção ao enfermo. Ressalta-se que este cuidador sofre prejuízos nos âmbitos emocionais, sociais, físicos e financeiros. Dentre os malefícios percebidos estão a vulnerabilidade destes cuidadores com relação a problemas de ansiedade e depressão.

Apesar de todo a dificuldade e sofrimento vivenciados, a família encontra-se em constante transformação sendo que diante às situações encontradas ela se reorganiza, se readaptando a fim de tornar-se novamente equilibrada.

Com base nisto, os cuidados paliativos surgem na tentativa de proporcionar ao paciente e seus familiares um olhar para sua dignidade, fornecendo apoio durante o processo de doença e suporte na ocorrência da morte. A partir do levantamento bibliográfico realizado observou-se que a equipe de cuidados, com o passar dos anos vem ampliando o olhar para este familiar tratando-os de forma holística, contudo ainda há necessidade de ampliar esta visão onde dar apoio, suporte, ouvi-los e principalmente informá-los sobre a doença e seu prognóstico são ações fundamentais.

Um olhar para a família significa humanizar a atenção na saúde, tratando a todos como seres biopsicossociais. É mister salientar a necessidade de novas pesquisas e apoio à área visto que há uma amplitude de intervenções possíveis e relativamente fáceis. Cabe, principalmente à psicologia, contribuir para este campo rico em sofrimento, entretanto repleto de possibilidades de alívio e suporte.

\section{Referências}

ANDRADE, C. G.; SANTOS, K. F. O.; COSTA, S. F. G.; FERNANDES, M. G. M.; LOPES, M. E. L.; SOUTO, M. C. Cuidados paliativos ao paciente idoso: uma revisão integrativa da literatura, Revista brasileira de Ciências da Saúde, São Caetado v. 16, n. 03, p. 411-418, 2012.

ARRIAZA, P.; CANCINO, G.; SANHUEZA, O. Pertenecer a algo mayor: experiencias de pacientes y cuidadores durante el cuidado paliativo en Chile, Ciencia y Enfermería, Concepcion, v.15, n.2, p. 95-106, 2009.

CAPELLO, E. M. C. S.; VELOSA, M. V. M.; SAlOTti, S. R. A.; GUIMARÃES, H. C. Q. C. P. Enfrentamento do paciente oncológico e do familiar/cuidador frente à terminalidade de vida, J. Revista Instituto de Ciências da Saúde, São Paulo, v. 30, n. 3, p. 235-240, 2012.

DURÓN, R. M.; MARTÍNEZ-JUÁREZ, I. E. Síndrome de desgaste del cuidador ¿estamos ayudando. Revista Médica Hondureña, Honduras, v. 77, n.1, p. 43-44, 2009.

FLORIANI, C. A.; SCHRAMM, F. R. Cuidador do idoso com câncer avançado: um ator vulnerado, Cadernos de Saúde Pública, São Paulo, v. 22, n.3, p. 527-534, 2006.

FONSECA, J. V. C.; REBELO, T. Necessidades de cuidados de enfermagem do cuidador da pessoa sob cuidados paliativos, Revista Brasileira de Enfermagem, São Paulo, v. 64, n. 1, p. 180-184, 2011. 
FRATEZI, F. R.; GUTIERREZ, B. A. O. Cuidador familiar do idoso em cuidados paliativos: o processo de morrer no domicílio, Ciência \& Saúde Coletiva, Rio de Janeiro, v. 16, n. 7, p. 3241-3248, 2011.

INOCENTI, A.; RODRIGUES, I. G.; MIASSO, A. I. Vivências e sentimentos do cuidador familiar do paciente oncológico em cuidados paliativos, Revista Eletrônica de Enfermagem, Goiânia, v. 11, n. 4, 2009.

MENDES, K. S.; SILVEIRA, R. C. C. P.; GALVÃO, C. M. Revisão integrativa: método de pesquisa para a incorporação de evidências na saúde e na enfermagem, Texto Contexto Enfermagem, Florianópolis, v. 17, n. 4, p. 758-64, 2008.

MENOSSI, M. J.; ZORZO, J. C. C.; LIMA, R. A. G. A dialógica vida/morte no cuidado do adolescente com câncer, Revista Latino-Americana de Enfermagem, São Paulo, v. 20, n. 1, p. 126-134, 2012.

NUNES, M. G. S. Assistência paliativa em oncologia na perspectiva do familiar: contribuições da enfermagem. 2010. 82 f. Dissertação (Mestrado) - Universidade do Estado do Rio de Janeiro, Rio de Janeiro. 2010.

NUNES, M. G. S.; RODRIGUES, B. M. R. D. Tratamento paliativo: perspectiva da família Revista de Enfermagem, Rio de Janeiro, UERJ, v. 20, n. 3, p. 338-343, 2012.

PEREZ, M. P.; SILVA, D. P. G.; COUTO, T. V. Percepções de um familiar de idoso hospitalizado na iminência de morte: um relato de caso, Arquivos de Ciências da Saúde, v.16, n. 1, p. 34-39, 2009.

REZENDE, V. L.; DERCHAIN, S. F. M.; BOTEGA, N. J.; SARIAN, L. O.; VIAL, D. L.; MORAIS, S. S. Depressão e ansiedade nos cuidadores de mulheres em fase terminal de câncer de mama e ginecológico, Revista Brasileira de Ginecologia de Obstetetrícia, Rio de Janeiro, v. 27, n. 12, p. 737-743, 2005.

REZENDE, V. L.; DERCHAIN, S.; BOTEGA, N. J.; SARIAN, L. O.; VIAL, D. L.; MORAIS, S. S.; PERDICARIS, A. A. M. Avaliação psicológica dos cuidadores de mulheres com câncer pelo General Comfort Questionnaire, Paidéia, Ribeirão Preto, v. 20, n. 46, p. 229-237, 2010. tab.
SALES, C. A.; D'ARTIBALE, E. F. O cuidar na terminalidade da vida: escutando os familiares, Ciênc. cuid. Saúde, v. 10, n. 4, 2011

SCHMIDT, B.; GABARRA, L. M.; GONÇALVES, J. R. Intervenção psicológica em terminalidade e morte: relato de experiência, Paidéia (Ribeirão Preto), v. 21, n. 50, p. 423-430, 2011.

SEKI, N. H.; GALHEIGO, S. M. O uso da música nos cuidados paliativos: humanizando o cuidado e facilitando o adeus, Interface - Comunicação, Saúde Educação, Botucatu, v. 14, n.33, p. 273-284, 2010.

SILVA, A. F.; ISSI, H. B.; MOTTA, M. G. C. A família da criança oncológica em cuidados paliativos: o olhar da equipe de enfermagem, Ciência \& Saúde Coletiva, Rio de Janeiro v. 10, n. 4, p. 820-827, 2011.

SILVA, C. A. M.; ACKER, J. I. B. V. O cuidado paliativo domiciliar sob a ótica de familiares responsáveis pela pessoa portadora de neoplasia, Revista Brasileira de Enfermagem, Brasília, v. 60, p. 2, p. 150-154, 2007.

SOARES, M. Cuidando da família de pacientes em situação de terminalidade internados na unidade de terapia intensiva, Revista Brasileira de Terapia intensiva, São Paulo, v. 19, p. 4, p. 481-484, 2007.

SOUZA, M. G. G.; GOMES, A. M. T. Sentimentos compartilhados por familiares de pacientes oncológicos em tratamento quimioterápico: um estudo de representações sociais, Revista de Enfermagem, Rio de Janeiro, v. 20, n. 2, p. 149-154, 2012 .

Recebido em: 26 ago. 2013. Aceito em: 22 abr. 2014. 
Encarnação, J. F.; Farinasso, A. L. C. 